Dr. Whitehead, in closing the discussion, pointed out the analogy with the problem of dielectries and discussed the Hopkinson superimposition principle. $\mathrm{He}$ also supported Dr. White's stressing of the importance of integral equations. He mentioned the importance of considering the energy aspects of rheological phenomena and added that he felt that British rheologists were at a disadvantage as a result of the lack of adequate journals for applied physics in Great Britain.

\section{PROTECTIVE MULTIPLE EARTHING}

TN 1941 the Council of the Institution of Electrical 1 Engineers set up a special committee to consider the problems arising from the increasing use of multiple earthing of the neutral conductor in factories and other buildings, and the report of the committee has now been published (J. Inst. Elec. Eng., 89, Pt. 1, No. 19 ; July, 1942). The report describes briefly the earthing protective methods generally employed in urban and rural areas and in cities, their advantages and disadvantages. Where underground cables are used, the sheathing and armouring of the cables are employed as the earth return path; alternatively, where available, continuous water mains with metal-to-metal joints may serve the purpose. Where neither of these is available, a separate earth electrode can be used at the consumer's premises although often the cost of an efficient earth is disproportionate to that of the electrical installation itself. Another method utilizes the supply company's low-voltage insulated neutral conductor, connexion being made thereto of each consumer's earthcontinuity conductor.

Protective multiple earthing consists of the lastmentioned method, with the addition of multiple connexions of the neutral conductor to earth at other positions on the low-voltage network, and of a connexion between the neutral conductor and earth at each consumer's premises; the earth continuity wire may be dispensed with but this is not recommended. Finally, miniature circuit breakers responsive to very small leakage currents are used.

The Committee's recommendations are as follows : (1) In areas where the supply authority's distribution network consists of underground cables, there should not be any relaxation, other than that contained in Regulation 4, of the Electricity Supply Regulations (1937), which requires earthing at one point only. (2) In areas where the supply authority's overhead distribution system is at low or medium voltage, and where it can be ensured that the distribution network and the consumers' installations are under the same control, so far as the earthing arrangements are concerned, protective multiple earthing would provide a satisfactory alternative to existing methods, and might be permitted. (3) Where the supply is separate from the supply authority's distribution network (that is, where a double-wound transformer or private generating plant is used), a multipleearthed neutral conductor might be permitted subject to specific conditions being imposed to provide against the risk of interference and possible damage to telephone circuits and apparatus, of gas pipes normally carrying current, of water pipes carrying anything but short-duration fault currents, and of light lead sheaths of telephone cables carrying power currents; these and other contingencies are outlined in an appendix.
Three appendixes are given : $(a)$ use of a multipleearthed neutral conductor where the supply is separate from the supply authority's distribution network; (b) protective devices responsive to very small leakage currents and actuating circuit breakers on the consumer's premises; and (c) definition of "connected with earth".

The report was submitted to the Electricity Com. missioners, who expressed the following views. When protective multiple earthing is adopted, all consumers' installations should comply with conditions as to earthing on the lines of those recommended in Technical Report $F / T$ No. 122 (1940) of the British Electrical and Allied Industries Research Association; in the case of consumers' installations existing at the date of adoption of such earthing, the responsibility for the installation complying with the conditions should rest upon the electricity undertakers. It would appear that the Wiring Regulations (Nucleus) Committee takes the view that there should be a continuing responsibility on the undertakers in respect of the condition of the consumer's installation, and if this be the case, the Commissioners in making regulations concerning protective multiple earthing will consider carefully to what extent they could properly impose such responsibility on the undertakers. The Commissioners are of the opinion that it is better, in view of the possible danger which the Committee has pointed out, that the earth connexion on live circuits should not be broken, and that no variation in practice in this respect should be made depending on the voltage of the circuit. They have decided, therefore, to make an appropriate amendment of Regula. tion 4 (iv) of the Electricity Supply Regulations (1937) on the lines of that suggested by the Committee, when a suitable opportunity occurs. When, on the grounds of cost or convenience, a link is not included in the earth connexion, the use of a suitably designed 'clip-on' ammeter should enable leakage tests to be carried out on live circuits without interrupting the connexion with earth.

\section{FORTHCOMING EVENTS}

\section{Friday, September 4}

Association of Scientific Workers (at Caxton Hall, Westminster, London, S.W.1) at 7 y.m. . Open meeting to discuss and support proposals for a Central Scientific and Technical Board. (The speakers will include Lord Strabolgi.)

\section{APPOINTMENTS VACANT}

Apploatrons are invited for the following appointments on or before the dates mentioned:

UNIVERSTTY CHAIR of CHEMTSTRY, tenable at the Royal Cancer Hospital - The Academic Registrar, University of London, Richmond College, Richmond, Surrey (September 1).

Junior EDvcatronal. Psychotogrst at the Child Guidance Centre of the Nottingham Education Committee-The Senior Medical Officer 28 Chaucer Street, Nottingham (September 2).

Assistant Lecturer in MEohanical Enginenring-The Registrar, College of Technology, Manchester 1 (September 7).

REGIUS Profiessor OF ENGINERRING at Edinburgh UniversityThe Private Secretary, Scottish Office, Fieldon House, 10 Great college Street, London, S.W.1 (September 7)

HEAD OF The CHemistry Departurent-The Principal and Clerk to the Governing Body, Wigan and District Mining and Technica College, Wigan (September 12).

HARRIS ChaIR of PHYsics, University College, Dundee-The Secretary, The University, St. Andrews (December 31).

LRCTURERS AND INSTRUCTORS YOR TRAINING Radio MechanicsLRCruRERS AND INSTRUCTORS FOR TRAINING RADIO MECHANI
The Principal, College of Technology and Arts, Eastlands, Rugby.

TEACHER FOR DAY AND EVENING ENGINEERING Classes-The Principal, County Technical College, Gainsborough, Lincs. 